\title{
The influence of polarized moonlight and collecting distance on the catches of winter moth Operophthera brumata (Lepidoptera: Geometridae) by light traps
}

\author{
LÁsZLó NOWINSZKY ${ }^{1}$, ANIKó HIRKA², GyÖRGY CSÓKA², GERGELY PETRÁNYI ${ }^{3}$ and JÁNOS PUSKÁS ${ }^{1}$ \\ ${ }^{1}$ University of West Hungary, Savaria University Centre, Károlyi Gáspár Square 4, H-9700 Szombathely, Hungary; \\ e-mail:1nowinszky@gmail.com,pjanos@gmail.hu \\ ${ }^{2}$ Hungarian Forest Research Institute, Department of Forest Protection, Hegyalja Street 18, H-3232 Mátrafüred, Hungary; \\ e-mail: csokagy@erti.hu, hirkaa@erti.hu \\ ${ }^{3}$ Corvinus University of Budapest, Department of Mathematics and Informatics, Villányi Road 29-33, H-1118 Budapest, Hungary; \\ e-mail: pertu.g@gmail.com
}

Key words. Lepidoptera, Geometridae, winter moth, Operophthera brumata, light trap, polarized moonlight, collecting distance

\begin{abstract}
In this study we examine the relationship between the Lunar Phases and the efficiency of light traps in catching winter moth (Operophthera brumata Linnaeus, 1758). Our calculations are based on data collected by the Hungarian Forestry Light Trap Network at four sites from 1961 to 2008. We also tried to estimate the influence of polarized moonlight and collecting distance, which also depends on moonlight. Our investigations revealed that the catches were the greatest in the First and the Last Quarters, and the lowest at Full Moon. The reason for this is that the proportion of polarized moonlight in the different lunar quarters varies, with the catches highest when the proportion is greatest. Collecting distance has only a minor role.
\end{abstract}

\section{INTRODUCTION}

It has been known for a long time that nocturnal insects orientate by means of moonlight. As noted by ancient observations ever since Aristotle, nocturnal insects are also attracted to artificial light. Scientists took advantage of this and constructed light traps. Among many other uses, light trap catches are useful in plant protection prognostics.

The majority of scientists working with light traps record a drop in the efficiency of the traps when there is a Full Moon, as against other lunar phases. Williams published fundamental studies in this field. According to Williams (1936), the following reasons might explain the smaller catches when there is a Full Moon: (1) Light from a lamp attracts moths from a smaller distance in a moonlit environment, or (2) Moths are less active in moonlit environments and so the active population available for a light trap to attract is smaller.

It is important to define and distinguish between the concepts of a theoretical and a true collecting distance (Nowinszky, 2008).

The theoretical collecting distance is the mean radius of the circle in the centre of which the trap is located and along the perimeter of which the illuminance caused by the artificial light source equals the illuminance of the environment.

The theoretical collecting distance depends on the luminous intensity of the artificial light source (candela), on the illuminance due to the Sun at dusk or dawn (the timing and length of twilights) and, over and above the illuminance caused by the nocturnal sky, on the periodically changing phase of the Moon. In recent decades, light pollution has had to be taken into account, the inten- sity of which may vary depending on the geographical position, season of the year or time of night.

The real collecting distance is influenced by the screening effect of the configuration of the terrain, objects, buildings and vegetation and presence of other light sources within the theoretical collecting distance. The real collecting distance also depends on the vagility (mobility), as well as the sensitivity of the insect species, which defines the maximum distance from which the insect can react to the light stimulus (Nowinszky, 2008).

The following authors explain the lower catches recorded when there is a Full Moon in terms of a shorter collecting distance: Bowden \& Curch (1973), Vaishampayan \& Shrivastava (1978), Vaishampayan \& Verma (1982), Nag \& Nath (1991). Shrivastava et al. (1987) also suggest that the lower catches of light traps when there is a Full Moon may be due to the stronger and brighter light of the Moon and a smaller collecting area, which are clearly physical phenomena.

On the other hand, the cited authors were living at a time when they did not have to consider the effect of light pollution. Recently we studied the effect of light pollution on the relationship between light trap catches of the European corn borer (Ostrinia nubilalis Hübner, 1796) and moonlight (Nowinszky \& Puskás, 2009). In this study we were unable to detect any influence of either collecting distance or flight activity. In accordance with the theory of El-Ziady, however, we assumed that these moths fly at greater heights at Full Moon, although, in the absence of light traps operating at different altitudes, this could not be proved.

According to Edwards (1961), measurements of the activity of insects depend on two factors. One is the pro- 
portion of the population that is active and the other is the amount of time spent flying by those that are active.

Similarly, but with greater precision, we define flight activity as follows (Nowinszky, 2008). Flight activity is the ratio of the proportion of specimens actually flying within the real collecting distance and thus available to be caught by a trap and the length of time the insects spend flying compared to the duration of trapping. By available specimens we mean the ones within the real collecting distance that fly when the trap is operational. If we accept this definition, then flight activity can be expressed numerically, namely, as the percentage of the available specimens flying multiplied by the percentage of the time they spend flying. However, the total number of individuals available to be caught by a trap is never known and the length of time they spend flying impossible to measure.

If we intend to estimate the degree of activity by visual observations, we may also encounter difficulties. So it is no surprise that the opinions of scientists on the role of moonlight on flight activity are rather controversial.

According to Rézbányai-Reser (1989), on moonlit nights when the Moon is above the horizon, moths often settle close to a trap before falling into it. However, general conclusions should not be drawn based on this observation. If, for example, we try to record the number of moths resting on vegetation in the vicinity of a trap at a Full Moon with the help of a torch, we also need to do the same thing at the same time of night at a New Moon, when the weather conditions are similar. Only then could we state that moths are less active at a Full than a New Moon.

Győrfi (1948) attributes the much smaller numbers of insects caught by light traps at Full Moon to decreased activity. Nemec (1971) is of the view that moths are inactive at Full Moon. Persson (1974) found that moonlight had a more marked effect in decreasing the flight activity of females than males. The study of Bowden \& Morris (1975) confirms the hypothesis, that insects are more active at Full Moon, because the catch is higher than that expected due to the decreased efficiency of the trap. Based on the results of their studies, Baker \& Sadovy (1978), Baker (1979) and Sotthibandhu \& Baker (1979) believe that moonlight cannot influence the collecting distance. Thus, in their view, light intensity moderates flight activity. On the other hand, the observations of Dufay (1964) contradict the theory that moonlight inhibits activity, as they record that nocturnal moths are attracted by car lights on moonlit nights and at Full Moon and although the numbers attracted to the lights decreases, it is never zero.

The cited authors examined the influence of activity only in the context of illuminance caused by the Moon and did not consider that the polarization of moonlight should be taken into account.

Research on the relationship between the numbers caught and the polarization of moonlight depends on proving that some insects orientate by polarized moonlight. In our earlier studies we pointed out that the high light trap catches in the First and Last Quarters can only be explained by the occurrence then of a higher ratio of polarized moonlight (Nowinszky et al., 1979; Nowinszky, 2008).

There is still no comprehensive answer to the dilemma of Williams (1936).

The winter moth (Operophthera brumata Linnaeus, 1758) flies from dusk (Szőcs, 1976) until midnight (Fenyves, 1960). Ambrus (1990) observed winter moths flying to light only from places very close to the light source. During pheromone trap experiments, Ambrus \& Csóka $(1988,1989,1992)$ found that one-third of marked adult winter moth males stayed within a $10 \mathrm{~m}$ radius even on the fourth day after marking. The longest distance they recorded a specimen flying to a trap was $70 \mathrm{~m}$. Based on these results, they think it is highly probable that light traps only catch moths from the immediate vicinity, so predictions of larger distances are not reliable. They hold this view even though aware of the fact that in outbreak years light traps catch tens of thousands of this species.

Because of the great deal of uncertainty in the scientific literature we decided to examine the way moonlight affects the light trap catches of winter moth. To do this we primarily considered the information on the behaviour of the species published in the studies of the abovementioned authors.

The winter moth Operophthera brumata Linnaeus, 1758 (Lepidoptera: Geometridae) is a univoltine, widely distributed Eurosiberian species that was also introduced into North America from Europe, with the first record from Nova Scotia in the 1950s and then the Pacific Northwest in the 1970s. It is a polyphagous species the larvae of which feed on many broadleaved trees and shrubs (Quercus, Fagus, Carpinus, Populus, Salix, Acer, Prunus, Betula, Alnus, Crataegus, Malus, etc.) and in Scotland they also feed and cause considerable damage to Sitka spruce, Picea sitchensis (Csóka, 1995). It is regularly one of the dominant species of the spring defoliator assemblages, and is a major defoliator of oaks in many countries in Europe (Csóka, 1995). In peak years the damage is recorded over tens of thousands of hectares in Hungary and the long term (1961-2009) average of the yearly damage is about 9,000 ha in Hungary (Hirka, 2009).

Cyclic outbreaks of winter moth occur in most of Europe, including Scandinavia. The outbreaks occur at 9-10 year interval (Leskó et al., 1999). Recently its outbreak range, most likely due to the climate change, has expanded to the north-east (Jepsen et al., 2008), therefore its importance will probably increase considerably in the near future. So it is important to monitor winter moth populations both from a theoretical and applied point of view.

Light traps are widely used in population studies of the winter moth. Although the wingless females are not caught, light trap catches can be used to provide damage forecasts (Leskó et al., 2008, 2009), but their reliability is dependent on an awareness of the environmental conditions that influence the catches. 
TABLE 1. Theoretical collecting distance and polarized moonlight depending on lunar phase angles.

\begin{tabular}{|c|c|c|c|c|}
\hline \multicolumn{3}{|c|}{ Lunar phase angles } & $\begin{array}{c}\text { Theoretical collecting } \\
\text { distance }(\mathrm{m})\end{array}$ & Polarized moonlight $\%$ \\
\hline $186-174$ & \pm 15 & $180^{\circ}=$ New Moon & 298.1 & \\
\hline $174-162$ & -14 & \multirow{6}{*}{ Waxing Crescent } & 298.1 & \\
\hline $162-150$ & -13 & & 298.1 & 3.563 \\
\hline $150-138$ & -12 & & 272.8 & 4.422 \\
\hline $138-126$ & -11 & & 178.6 & 5.365 \\
\hline $126-114$ & -10 & & 131.1 & 6.000 \\
\hline $114-102$ & -9 & & 104.4 & 6.324 \\
\hline $102-90$ & -8 & \multirow{2}{*}{$90^{\circ}=$ First Quarter } & 81.6 & 6.576 \\
\hline $90-78$ & -7 & & 65.2 & 6.285 \\
\hline $78-66$ & -6 & \multirow{6}{*}{ Waxing Gibbous } & 53.7 & 5.788 \\
\hline $66-54$ & -5 & & 46.0 & 4.950 \\
\hline $54-42$ & -4 & & 39.1 & 3.687 \\
\hline $42-30$ & -3 & & 33.6 & 2.412 \\
\hline $30-18$ & -2 & & 28.9 & -0.412 \\
\hline $18-6$ & -1 & & 24.6 & -0.115 \\
\hline $6-354$ & 0 & $0^{\circ}$ or $360^{\circ}=$ Full Moon & 21.1 & 0 \\
\hline $354-342$ & 1 & \multirow{6}{*}{ Waning Gibbous } & 21.6 & -1.115 \\
\hline $342-330$ & 2 & & 24.8 & -0.041 \\
\hline $330-318$ & 3 & & 28.4 & 2.511 \\
\hline $318-306$ & 4 & & 33.8 & 3.927 \\
\hline $306-294$ & 5 & & 39.4 & 5.412 \\
\hline 294-282 & 6 & & 46.0 & 6.869 \\
\hline $82-270$ & 7 & \multirow{2}{*}{$270^{\circ}=$ Last Quarter } & 55.1 & 7.941 \\
\hline $270-258$ & 8 & & 66.8 & 8.714 \\
\hline $269-246$ & 9 & \multirow{6}{*}{ Waning Crescent } & 82.3 & 8.765 \\
\hline $246-234$ & 10 & & 133.7 & 7.212 \\
\hline $234-222$ & 11 & & 222.8 & 6.083 \\
\hline $222-210$ & 12 & & 252.6 & 4.939 \\
\hline $210-198$ & 13 & & 298.0 & \\
\hline $198-186$ & 14 & & 298.0 & \\
\hline $186-174$ & \pm 15 & $180^{\circ}=$ New Moon & 298.0 & \\
\hline
\end{tabular}

Notes: A few days after a New Moon, the Moon is visible again in the Waxing Crescent phase that lasts until the First Quarter. The Waxing Gibbous Moon occurs between the First Quarter and Full Moon. The Sun illuminates more than half of the Moon's surface during this period. The period between Full Moon and the Last Quarter is called the Waning Gibbous phase. The illuminated portion of the Moon goes down from $100 \%$ to $50 \%$ during this period. The Waning Crescent phase is the period between the Last Quarter and the next New Moon. The Sun illuminates less than half of the Moon during this period.

\section{MATERIAL AND METHODS}

To create lunar phase divisions, we downloaded temporal data on Full Moons from the website of the Astronomical Applications Department of the US Naval Observatory (http:// aa.usno.navy.mil/cgi-bin/aap ap.pl). Data on the rising and setting of the Moon and lunar phases were downloaded from: http://aa.usno.navy.mil/cgi-bin/aa_pap.pl. We arranged data on the relative polarization of moonlight into phase angle divisions based on the study by Pellicori (1971).

Data on the illuminance of the environment were calculated using our own software. This software for TI 59 computers was developed by the late astronomer G. Tóth specifically for our joint work at that time (Nowinszky \& Tóth, 1987). The software was transcribed for modern computers by M. Kiss. The software calculates the illumination in terms of lux of the Sun at dusk, the light of the Moon and the illuminance of a starry sky for any given geographical location, day and time, separately or summarized. It also considers cloudiness.

All our data on cloud cover were taken from the Annales of the Hungarian Meteorological Service. The data in these books are oktas of cloud cover (eighth part) recorded every $3 \mathrm{~h}$.

In addition, data on light pollution were taken into consideration when calculating theoretical collecting distances. In our earlier work (Nowinszky, 2006, 2008), we estimated light pollu- tion based on the study of Cinzano et al. (2001) and lunar illumination. For this study the average illumination at Full Moon and in the First Quarter were calculated. The theoretical collecting distance can be calculated using the following formula:

$$
r_{0}=\sqrt{\frac{I}{E_{N}+E_{H}+E_{C S}+E_{F}}}
$$

where: $r_{0}=$ theoretical collecting distance, $I=$ illuminance from the lamp [candela], $E=$ the illuminance of the environment [lux], which is the light from the setting or rising Sun $\left(E_{N}\right)$, Moon $\left(E_{H}\right)$, starry sky $\left(E_{C S}\right)$ and light pollution $\left(E_{F}\right)$.

In the present study we did not include light pollution in our calculations, as of the available data on 28 adult broods only 8 were for years after 1982 and in the years before that light pollution is likely to have been quite moderate. We defined the concept of real collecting distance as the part of the theoretical collecting distance in which the catch is increasing.

As the proportion of polarized moonlight is highest in the First and the Last Quarters, we had to determine whether moths can see the Moon in these lunar phases in order to be able to examine the influence of polarized moonlight (Table 1). In the First Quarter they obviously can, as on these days the Moon is visible in the evening, but in the Last Quarter, in most cases only after midnight. Therefore, based on data on the rising and setting of the Moon in the period close to the Last Quarter, we 
TABLE 2. The locality and geographical position of the light traps and the period over which they were operated.

\begin{tabular}{cccc}
\hline Locality & Latitude & Longitude & Years of operation \\
\hline Felsötárkány & $47.98 \mathrm{~N}$ & $20.43 \mathrm{E}$ & $1961-2008$ \\
Répáshuta & $48.04 \mathrm{~N}$ & $20.52 \mathrm{E}$ & $1962-2008$ \\
Szentpéterfölde & $46.61 \mathrm{~N}$ & $16.75 \mathrm{E}$ & $1968-2008$ \\
Várgesztes & $47.46 \mathrm{~N}$ & $18.38 \mathrm{E}$ & $1962-2008$ \\
\hline
\end{tabular}

determined whether each flight occurred only if the Moon was above the horizon before midnight, the period when this species is active.

We processed the catches of winter moth in the database of the Forestry Light Trap Network for the period between 1961 and 2008. The 4 observation sites chosen were those where the traps have been working continuously for the longest time, which are: Felsőtárkány, Répáshuta, Szentpéterfölde and Várgesztes (Table 2). There are great differences in the numbers of specimens caught each year even by traps in the same locality. This may distort the results even if the number of specimens caught or derived relative catches are included in the calculations. To avoid this distortion, we only included the catches of traps that caught at least 500 specimens. In this way, we could at least work with specimen numbers of the same order of magnitude when calculating the relative catches.

We had a total of 838 catches of a total of 54089 specimens from 28 broods available for analysis.

The observation data consists of the mean nightly catches of one trap. Only nights and hours when some winter moths were caught were included in the calculations, as our earlier studies indicated that although the Moon influences the efficiency of trapping, it never makes collecting impossible (Nowinszky, 2003).

For every night of the flight periods (UT $=0 \mathrm{~h}$ ) we calculated phase angle data of the Moon at midnight. Of the 360 phase angle degrees of the full lunation we established 30 phase angle divisions. The phase angle division including that of a Full Moon $\left(0^{\circ}\right.$ or $\left.360^{\circ}\right)$ and values $0 \pm 6^{\circ}$ was designated 0 . Beginning from this group through the First Quarter until a New Moon, divisions were marked as $-1,-2,-3,-4,-5,-6,-7,-8$, $-9,-10,-11,-12,-13$ and -14 . The next division is \pm 15 , including the New Moon. From the Full Moon through the Last Quarter in the direction of the New Moon divisions, were designated $1,2,3,4,5,6,7,8,9,10,11,12,13$ and 14. Each division consists of 12 degrees (Nowinszky, 2003). These phase angle divisions can be related to the four quarters of lunation as follows: Full Moon ( -2 to +2 ), Last Quarter (3 to 9), New Moon $(10$ to -10$)$ and First Quarter ( -9 to -3$)$. The nights and hours of the periods under examination were all classed in these phase angle divisions.

Based on the number of specimens trapped, we calculated relative catch values by species and by broods. Relative catch (RC) is the ratio of the number of specimens caught in a given sample unit of time ( $1 \mathrm{~h}$ or $1 \mathrm{night})$ and the average number of specimens caught in the same time unit calculated for the whole brood. If the number of specimens trapped equals the average, the value of relative catch is one. We calculated three-point moving averages from the relative catch data.

The use of moving averages is justified whenever the independent variable is made up of data representing a wide range of values that are to be contracted into classes. This is because the dividing line between these classes is always drawn more or less arbitrarily. Besides, extreme values in two neighbouring classes of the independent variable are always closer to each other than they are to the middle value of their own class. Working with moving averages ensures a degree of continuity between the data of our arbitrarily established classes and, at least partially, eliminates the disturbing influence of other environmental factors not examined in a given context (Nowinszky, 2003).

We have sorted relative catch values into the proper phase angle divisions and averaged them. We depict the results and indicate the regression curve, its parameters and the significance levels in the figures.

Consequently, to examine the influence of polarized moonlight and the theoretical collecting distance on catch results we have divided lunation into two sections, one from New to Full Moon including the First Quarter (waning), and the other from Full to New Moon including the Last Quarter (waxing). This was important because in the First and the Last Quarters the distribution of both moonlight and its polarized proportion are asymmetrical.

We have previously associated the percentage value of the proportion of polarized moonlight with different phase angle divisions (Nowinszky et al., 1979).

With the help of our special software, we calculated environmental illumination values associated with the phase angle divisions and from these generated theoretical collecting distances. For these calculations we assumed an average cloud cover of 5 oktas.

In addition, for the waning and waxing section of each lunar month we analysed the correlation between the 3 point moving average of relative catch values and polarized moonlight. In the same way we examined the relationship between the 3 point moving average of relative catch values and the theoretical collecting distance. In every case we calculated significance levels for the correlation coefficients. The results were plotted on graphs.

\section{RESULTS}

In Fig. 1 the 3 point moving average of relative catch values as a function of lunar phases are depicted. The relationship between polarized moonlight and the catch is shown in Figs 2-3, while that of collecting efficiency and theoretical collecting distance in Figs 4-5.

For the sake of interpretation of our results we have calculated correlation coefficients for polarized moonlight and theoretical collecting distance. These are as follows:

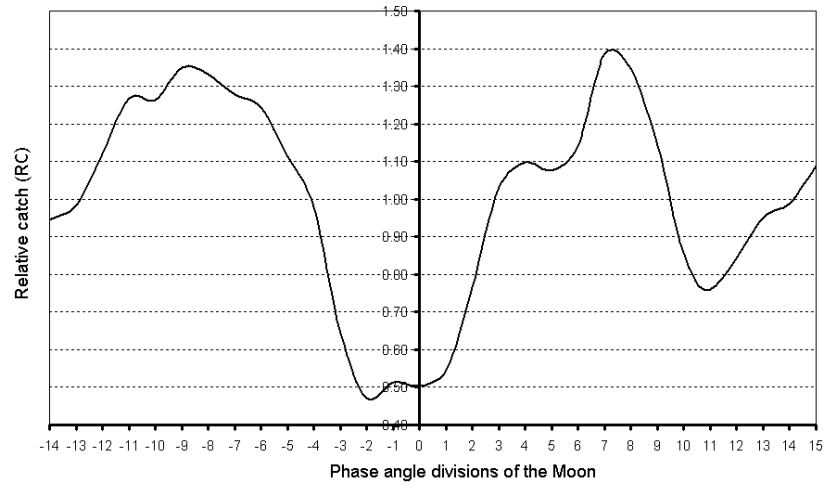

Fig. 1. The light trap catches of winter moth (Operophthera brumata L.) depending on the phases of the moon. 


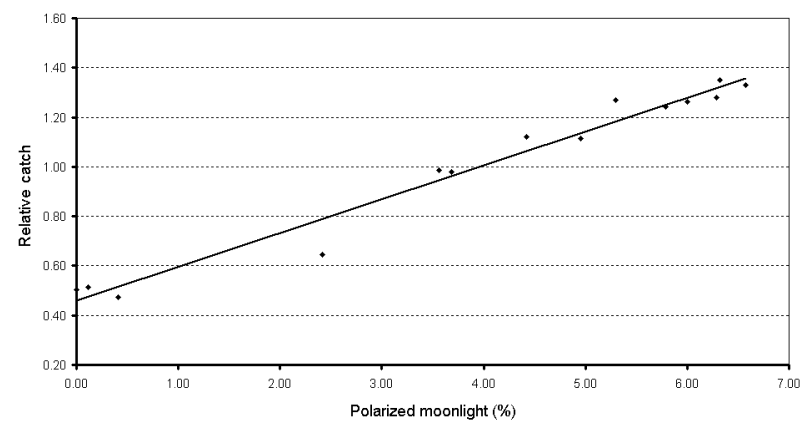

Fig. 2. The light trap catches of winter moth (Operophthera brumata L.) depending on polarized moonlight between New and Full Moon.

In the waning section, when the ratio of polarized moonlight is between 0 and $5.788 \%$ and the theoretical collecting distance between 27.9 and $98 \mathrm{~m}, \mathrm{r}=0.9219$ and $\mathrm{P}<0.001$; when the ratio of polarized moonlight is between $0-6.576 \%$ and the theoretical collecting distance between $27.9-313 \mathrm{~m}, \mathrm{r}=0.7708$ and $\mathrm{P}<0.01$.

In the waxing section, polarized moonlight: $0-6083 \%$, theoretical collecting distance: $27.9-124.3 \mathrm{~m}, \mathrm{r}=0.8307$ and $\mathrm{P}<0.05$; polarized moonlight: $0-8.765 \%$, theoretical collecting distance: 27.9-262.1 m, r $=0.899$ and $\mathrm{P}<$ 0.001 .

\section{DISCUSSION}

Fig. 1 shows two peaks in light trap catches of the winter moth (Operophthera brumata Linnaeus, 1758) in the vicinity of the First and Last Quarter. According to the studies of Szőcs (1976) and Fenyves (1960), this moth is only active from dusk until about midnight. Therefore, in the First Quarter, specimens can see the Moon every night, but in the Last Quarter, when most nights the Moon rises only after midnight, the catch maximum lacks an explanation. For this reason, we examined the time of the rising and setting of the Moon for each brood. We found that in the case of broods where there was a catch peak in the Last Quarter, the Moon was above the horizon before midnight, so the moths might have sensed polarized moonlight for some time. On the other hand, in the case of broods where there was no catch peak in the Last Quarter, the Moon only rose after midnight. Our results

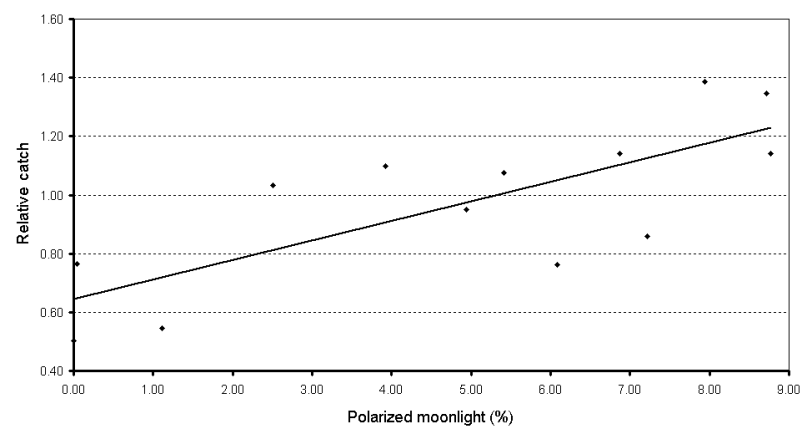

Fig. 3. The light trap catches of winter moth (Operophthera brumata L.) depending on polarized moonlight between Full and New Moon.

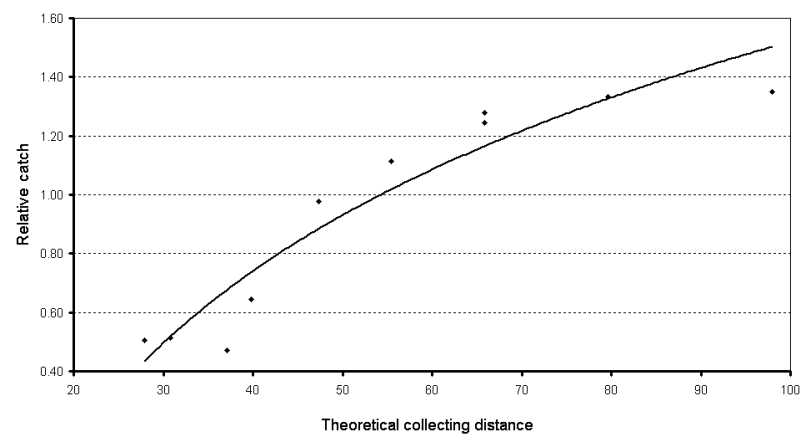

Fig. 4. The light trap catches of winter moth (Operophthera brumata L.) depending on the theoretical collecting distance between New and Full Moon.

on the influence of polarized moonlight confirm the results of Nowinszky (2008), namely:

The reason for the catch minimum observed during Full Moon may not be a relatively strong illuminance caused by the Moon. Most insects take wing at dusk and the illuminance values recorded during different twilights are higher than those due to moonlight.

Based on the works of Dacke et al. (2003), Gál et al. (2006) and Hegedüs et al. (2006) we can presume that a high ratio of polarized moonlight presents more information for the orientation of insects than a smaller proportion of either positively or negatively polarized moonlight around the time of Full Moon. This may be the reason for the high catches in the First and last Quarters and low ones during a Full Moon.

The illuminance due to moonlight at a Full Moon does not generally decrease the flight activity of insects, as proposed by Williams (1936). The point is rather that at a Full Moon flight activity truly decreases, as compared to that during the First and the Last Quarters. This might be caused by the difference in the volume of polarized moonlight, the highest during the First and the Last Quarters and the lowest at a Full Moon.

Our new results indicate that catches are high when the proportion of polarized moonlight is high (Figs 2-3). Based on our study, we can complete and partially modify the presumption of Williams (1936), that strong moonlight decreases flight activity. Our results indicate that when a high proportion of moonlight is polarized, flight

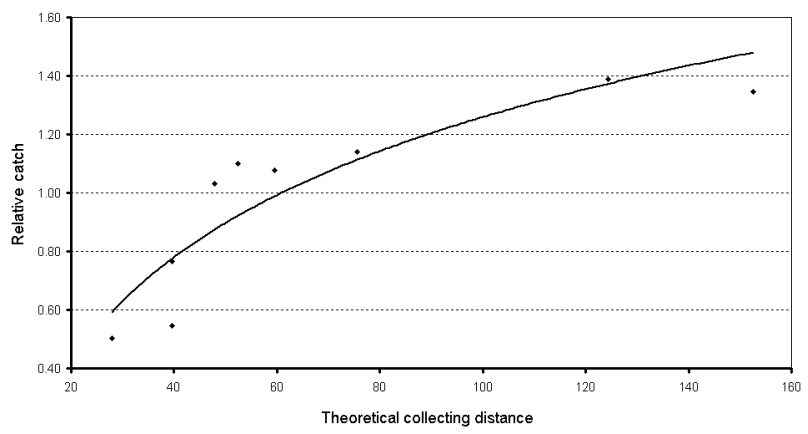

Fig. 5. The light trap catches of winter moth (Operophthera brumata L.) depending on the theoretical collecting distance between Full and New Moon. 
activity increases but when there is a low level of polarization, as at a Full Moon, flight activity decreases.

Studies by Ambrus (1990) and Ambrus \& Csóka (1988, 1992) show that winter moths fly to light traps from only a very short distance. Our results illustrated in Figs 4-5, plotting catch results as a function of theoretical collecting distance, seem to contradict this theory. According to these, an increase of catch may be observed up to 124 $\mathrm{m}$ from the trap. Therefore, we should consider this as the real collecting distance. On the other hand, in the chapter on results we have shown polarized moonlight to be closely and significantly related to the theoretical collecting distance. Thus, the contradiction with the results of the above mentioned authors may only be apparent. The increase in the catch might be due to the influence of polarized moonlight rather than collecting distance. This is also indicated by the very low and insignificant correlation $(\mathrm{r}=0.177)$ between trap catches and collecting distance for a whole lunation.

In conclusion, light trap catches of winter moth are markedly influenced by changes in the level of polarized moonlight during the course of a lunar cycle.

ACKNOWLEDGEMENT. We thank M. Kiss, who transcribed our software for modern computer.

\section{REFERENCES}

Ambrus A. 1990: Investigations on Insect Population with Recapture Methods. Ph.D. thesis, Sopron University, 101 pp. [in Hungarian].

Ambrus A. \& CsóKA Gy. 1988: Investigations on the swarming of winter moth (Operophthera brumata L.) by the aid of pheromone traps. Erdészeti Kutatások 80-81: 167-172 [in Hungarian].

Ambrus A. \& CsóKA Gy. 1992: Studien über das Schwärmen und die Dichte-Abschätzung des Forstspanners, Operophthera brumata L. (Lep., Geometridae) mit Hilfe von Markierungen und Pheromonfallen in Ungarn. Anz. Schädlingsk. Pflanzensch. Umweltsch. 65: 88-92.

BAKER R.R. 1979: Celestial and light-trap orientation of moths. Antenna 3: 44-45.

BAKER R.R. \& SAdOVY Y. 1978: The distance and nature of the light-trap response of moths. Nature 276: 818-821.

Bowden J. \& Church B.M. 1973: The influence of moonlight on catches of insects in light-traps in Africa. Part II. Bull. Entomol. Res. 63: 129-142.

BOWDEN J. \& Morris G.M. 1975: The influence of moonlight on catches of insects in light-trap in Africa. Part III. The effective radius of a mercury-vapour light-trap and analysis of catches using effective radius. Bull. Entomol. Res. 65: 303-348.

Cinzano P., Falchi F. \& Elvidge C.D. 2001: The first world atlas of the artificial night sky brightness. Mon. Not. R. Astron. Soc. 328: 689-707.

Dacke M., Nilsson D.E., Scholtz C.H., Byrne N. \& Warrant E.J. 2003: Insect orientation to polarized moonlight. Nature 424: 33 .

Dufay C. 1964: Contribution à l'Étude du phototropisme des Lépidoptères noctuides. Ann. Sci. Nat. (Zool.) 12: 281-406.

EDWARDS J.S. 1961: Observations on the ecology and behaviour of the huhu beetle, Prionoplus reticularis White. (Col.: Ceramb.). Trans. R. Soc. N. Z. 88: 733-741.
El-Ziady S. 1957: A probable effect of the moonlight on the vertical distribution of Diptera. Bull. Soc. Entomol. Egypte 41: 655-662.

Fenyves P. 1960: Cultivation of Fruit Trees. Mezőgazdasági Kiadó, Budapest [in Hungarian].

Gál J.G., Horváth G., Barta A. \& Wehner R. 2001: Polarization of the moonlit clear night sky measured by full-sky imaging polarimetry at full moon: comparison of the polarization of moonlit and sunlit skies. J. Geophys. Res. 106: 22647-22653.

GYöRFI J. 1948: The influence of illumination and light on insects. Erdészeti Kísérletek 48: 108-111 [in Hungarian].

Hegedűs R., Szél Gy. \& Horváth G. 2006: Imaging polarimetry of the circularly polarizing cuticle of scarab beetles (Coleoptera: Rutelidae, Cetoniidae). Vision Res. 46: 2786-2797.

NAG A. \& Nath P. 1991: Effect of moon light and lunar periodicity on the light trap catches of cutworm Agrotis ipsilon. $J$. Appl. Entomol. 111: 358-360.

NEMEC S.J. 1971: Effects of lunar phases on light-trap collections and populations of bollworm moth. J. Econ. Entomol. 64: $860-864$.

NowinszKy L. (ed.) 2003: The Handbook of Light Trapping. Savaria University Press, Szombathely, 272 pp.

NowINSZKY L. 2006: The light pollution and the light trapping of insects. Dissertat. Savarien. 36: 1-34.

NowinszKY L. 2008: Moonlight and lunar phases. In Nowinszky L. (ed.): Light Trapping and the Moon. Savaria University Press, Szombathely, pp. 47-104.

NowinszKY L. \& PUSKÁs J. 2009: Light-trap catch of European Corn Borer (Ostrinia nubilalis Hbn.) depending on the moonlight. Acta Entomol. Serb. 14: 163-174.

Nowinszky L. \& Tóth Gy. 1987: Influence of Cosmic Factors on the Light-trap Catches of Harmful Insects. Ph.D. Thesis, Savaria University, Szombathely, 123 pp. [in Hungarian].

Nowinszky L., Szabó S., Tóth Gy., Eкк I. \& Kiss M. 1979: The effect of the moon phases and of the intensity of polarized moonlight on the light-trap catches. Z. Angew. Entomol. 88: 337-353.

Pellicori S.F. 1971: Polarizing properties of pulverized materials with special reference to the lunar surface. Applied. Optics. 10: 270-285.

ReZBANYAI-RESER L. 1989: Lichtanflug von Tagfaltern und anderen tagaktiven Macrolepidopteren in der Schweiz (1972-1988) (Lepidoptera: Rhopalocera und Macroheterocera). Nota Lepidopt. 12: 36-44.

Shrivastava S.K., Shukla B.C. \& Shastri A.S.R.A.S. 1987: Effects of lunar cycle on light trap catches of Spodoptera litura Fabricius. Indian J. Agric. Sci. 57: 117-119.

SotThibandHU S. \& BAKER R.R. 1979: Celestial orientation by the large yellow moth, Noctua pronuba L. Anim. Behav. 27: 786-800.

Szöcs G. 1976: The life of the winter moth (Operophthera brumata L.). Állattani Közlemények 83: 237-238 [in Hungarian].

VAishampayan S.M. \& Shrivastava S.K. 1978: Effect of moon phase and lunar cycle on the light trap catch of tobacco caterpillar Spodoptera litura (Fabr.) (Lepidoptera: Noctuidae). $J$. Bombay Nat. Hist. Soc. 75: 83-87.

VAISHAMPAYAN S.M. \& Verma R. 1982: Influence of moon light and lunar periodicity on the light trap catches of gram podborer, Heliothis armigera (Hubner) moths. Indian J. Entomol. 44: 206-212.

WiLLIAMS C.B. 1936: The influence of moonlight on the activity of certain nocturnal insects, particulary of the family of Noctuidae as indicated by light-trap. Phil. Trans. R. Soc. Lond. (B) 226: 357-389.

Received July 5, 2010; revised and accepted September 2, 2011 